\title{
Src family kinase activity regulates adhesion, spreading and migration of pancreatic endocrine tumour cells
}

\author{
Alessia Di Florio, 2,3 Gabriele Capurso ${ }^{2}$, Massimo Milione $^{2}$, \\ Francesco Panzuto ${ }^{2}$, Raffaele Geremia ${ }^{1,3}$, Gianfranco Delle Fave ${ }^{2}$ \\ and Claudio Sette ${ }^{1,3}$
}

\footnotetext{
${ }^{1}$ Department of Public Health and Cell Biology, University of Rome Tor Vergata, Via Montpellier, 1, 00133 Rome, Italy ${ }^{2}$ Digestive and Liver Disease Unit, II Medical School, University of Rome La Sapienza, Rome, Italy

${ }^{3}$ Institute of experimental Neuroscience, IRCCS Fondazione Santa Lucia, Rome, Italy

( Requests for offprints should be addressed to G D Fave who is now at Digestive and Liver Disease Unit, II Medical School, University of Rome La Sapienza, Rome, Italy; Email: gianfranco.dellefave@ uniroma1.it); C Sette is now at Department of Public Health and Cell Biology, University of Rome Tor Vergata, Via Montpellier, 1, 00133 Rome, Italy
}

\begin{abstract}
Pancreatic endocrine tumours (PETs) are rare and 'indolent' neoplasms that usually develop metastatic lesions and exhibit poor response to standard medical treatments. Few studies have investigated pathways responsible for PET cell growth and invasion and no alternative therapeutic strategies have been proposed. In a recent microarray analysis for genes up-regulated in PETs, we have described the up-regulation of soluble Src family tyrosine kinases in this neoplasia, which may represent potentially promising candidates for therapy. Herein, we have investigated the expression and function of Src family kinases in PETS and PET cell lines. Western blot analysis indicated that Src is highly abundant in the PET cell lines CM and QGP-1. Immunohistochemistry and Western blot analyses showed that Src is up-regulated also in human PET lesions. Pharmacological inhibition of Src family kinases by the specific inhibitor PP2 strongly interfered with adhesion, spreading and migration of PET cell lines. Accordingly, the actin cytoskeleton was profoundly altered after inhibition of Src kinases, whereas even prolonged incubation with PP2 exerted no effect on cell cycle progression and/or apoptosis of PET cells. A transient increase in tyrosine phosphorylation of a subset of proteins was observed in QGP-1 cells adhering to the plate, with a peak at 75 min after seeding, when approximately $80 \%$ of cells were attached. Inhibition of Src kinases caused a dramatic reduction in the phosphorylation of proteins with different molecular weight that were isolated from the cell extracts by anti-phosphotyrosine immunoprecipitation or pull-down with the $\mathrm{SH} 2$ domain of Src. Among them, the docking protein p130Cas interacted with Src and is a major substrate of the Src kinases in QGP-1 cells undergoing adhesion. Our results suggest that Src kinases play a specific role during adhesion, spreading and migration of PET cells and may indicate therapeutical approaches directed to limiting the metastatic potential of these cells.
\end{abstract}

Endocrine-Related Cancer (2007) 14 111-124

\section{Introduction}

Pancreatic endocrine tumours (PETs) are rare neoplasms arising from pancreatic islet cells. PETs are classified as 'functioning' (F) or 'non-functioning' (NF) depending on the presence or absence of a syndrome due to excessive hormone secretion from cancer cells (Plockinger et al. 2004). Although PETs are considered to be 'indolent' tumours, at the time of diagnosis approximately $60 \%$ of NF PETs patients have liver metastases, which represent the most important factor determining their outcome (Panzuto et al. 2005, Tomassetti et al. 2005). In patients with metastatic, progressive PETs, therapy with somatostatin analogues is poorly effective, with only $27 \%$ response (Panzuto et al. 2006). Moreover, due to their slow proliferation kinetics, chemotherapy plays a secondary role in PETs (O'Toole et al. 2004). Since the molecular pathways 
related to PETs growth and invasion are poorly understood, no alternative therapeutic strategies based on specific targets have been explored for these diseases. In an attempt to identify novel biomarkers and therapeutic targets for PETs, gene expression profiles were obtained from a homogeneous group of metastatic, progressive, NF PETs and have led to the observation that Src family tyrosine kinases are often up-regulated at the mRNA level (Capurso et al. 2006).

The Src family of tyrosine kinases comprises nine members: Src, Lck, Fyn, Yes, Hck, Blk, Fgr, Lyn and Yrk (Thomas \& Brugge 1997). These kinases act downstream of growth factor receptors and integrins and are implicated in several aspects of cell growth and metabolism, ranging from cell cycle regulation to cell adhesion and motility (Thomas \& Brugge 1997, Playford \& Schaller 2004). They contain two highly conserved protein interaction domains, the $\mathrm{SH} 2$ and SH3 domains, located upstream of the kinase lobe. The SH2 domain allows Src kinases to interact with tyrosine phosphorylated residues, whereas the SH3 domain binds to proline-rich sequences. Both domains participate in the regulation of Src family kinases activity and are required to interact with several substrates and to localize to discrete subcellular locations (Thomas \& Brugge 1997). Following growth factor stimulation, protein-protein interactions with membrane receptor and/or downstream signalling effectors displace auto-inhibitory interactions of the SH2 and SH3 domain with the kinase lobe and release the fully active Src (Thomas \& Brugge 1997). Dephosphorylation of the autoinhibitory tyrosine 527 by tyrosine phosphatases like PTP $\alpha$ contribute to maintain Src in its active state (Ponniah et al. 1999).

Adhesion to the extracellular matrix (ECM) is a fundamental process for both normal and neoplastic cells (Malliri \& Collard 2003, Cavallaro \& Christofori 2004). Cell adhesion and spreading is mediated by the interaction of transmembrane integrin molecules and the ECM (Giancotti \& Tarone 2003). A complex array of proteins are then recruited to the cell membrane and are involved in the assembly of the actin cytoskeleton around the site of cell attachment. The catalytic activity of tyrosine kinases like Src, Fyn and the focal adhesion kinase FAK are required for these events (Playford \& Schaller 2004). Interestingly, in several cell types, FAK directly recruits $\mathrm{Src}$ to the focal adhesion sites (Schaller et al. 1994, Thomas et al. 1998) and Src potentiates activation of FAK through phosphorylation of additional tyrosine residues (Schlaplafer et al. 1994, Calalb et al. 1995). Tyrosine phosphorylation of FAK and integrin molecules creates docking sites for other proteins involved in actin cytoskeleton remodelling, like the scaffold protein p130Cas, paxillin and p190RhoGAP (Playford $\&$ Schaller 2004). A role for Src in cell adhesion and motility of fibroblasts was indicated by the observation that transformation with the constitutively active v-Src causes a round morphology and detachment from the ECM (Rohrschneider 1980). On the other hand, fibroblasts harbouring null mutations in the Src, Fyn and Yes genes are defective in focal adhesion turnover and cell migration (Webb et al. 2004).

In line with its oncogenic potential, the activity of several Src family kinases is increased in a multitude of primary tumours and metastatic lesions (Irby et al. 1999, Irby \& Yeatman 2000, Yeatman 2004). More recently, it has been shown that Src enhances pancreatic adenocarcinoma cell adhesion to the ECM through the $\alpha \mathrm{v} \beta 3$ integrin complex (Duxbury et al. 2004a). Furthermore, inhibition of Src was shown to sensitize pancreatic adenocarcinoma cells to chemotherapic agents both in culture and in vivo (Duxbury et al. 2004b, Yezhelyev et al. 2004). However, no data are currently available on the role of Src family kinases in PETs. Moreover, information on the interaction of PET cells with the ECM is also scarce.

Herein, we have investigated the expression and function of Src family kinases in two available PET cell line models and PET lesions. Our experiments show that Src is highly expressed in PETs and PET cell lines and is required for both PET cell adhesion to the ECM and their spreading and migration.

\section{Materials and methods}

\section{Cell culture and reagents}

The human PET cell line QGP-1, derived from a somatostatinoma was obtained from Cancer Research UK Cell Services; and CM, which originates from an insulinoma, was kindly provided by Dr Marco Baroni (Rome, Italy). QGP-1 and CM cells were grown at $37{ }^{\circ} \mathrm{C}$ in a humidified $5 \% \mathrm{CO}_{2}$ atmosphere in Roswell Park Memorial Institute (RPMI) 1640 medium (BioWhittaker Cambrex Bioscience, Belgium) supplemented with 10 and 5\% fetal bovine serum (FBS; Gibco BRL, Invitrogen) respectively. For adhesion, assays were collected after application of trypsin/EDTA (Gibco BRL) for $1 \mathrm{~min}$ and seeded on noncoated or coated plates in complete medium or serumfree medium respectively. The cells were incubated with either $0.1 \%$ dimethyl sulfoxide (DMSO; SigmaAldrich) or $10 \mu \mathrm{M}$ PP2 (4-amino-5-(4-chlorophenyl)7(t-butyl)pyrazolo[3,4-d]pyrimidine; Calbiochem, San Diego, CA, USA) during adhesion. 


\section{Immunohistochemistry}

Immunohistochemical analysis (IHC) was performed on formalin-fixed, paraffin-embedded tissue sections from 27 PETs (17 primaries, 10 metastases) from 24 individual patients. All samples, except for four insulinomas, were from patients with NF-PETs. According to the WHO guidelines (Solcia et al. 2000), there were six well-differentiated endocrine tumour (WDETs), twenty well-differentiated endocrine carcinoma (WDECs) and two poorly-differentiated endocrine carcinoma (PDECs). The expression of Src was also analysed in normal islet cells identified in the same samples and in three normal pancreatic samples negative for tumour invasion. All samples were first analysed histologically, and subsequently with several markers and Ki-67 as described previously (Capurso et al. 2005). Subsequent IHC analysis was performed with a rabbit anti-Src antibody (Cell Signalling Technology, Beverly, MA, USA) at working dilution in the ratio of 1:100. Src antibody was optimized on both human colorectal cancer specimens. To ensure antibody specificity, consecutive sections were incubated in the absence of primary antibody and showed no immunostaining. The immunoreactivity for Src was evaluated on a semiquantitative scale considering both the percentage of positive cells (score: 0-4 for respectively, $<5,5-20,20-40,40$ $80,>80 \%$ ) and the intensity (score: $0-3$ ) of staining. The product of both yield a final immunostaining score (range: 0-12). The immunostaining was visualized using the EnVision polymer method (DakoCytomation, Hamburg, Germany) followed by haematoxylin counterstaining.

\section{Statistical analysis}

Src immunostaining scores were continuous data expressed as the mean (95\% confidence interval, CI) in different subgroups and evaluated by $t$-test. Correlation between the IHC score and other factors was evaluated with the Spearman's rank correlation test; a $P$ value $<0.05$ was considered statistically significant.

\section{Flow cytometry}

At the appropriate time, cells were fixed in $1 \%$ paraformaldehyde for $30 \mathrm{~min}$, washed in PBS and incubated for $16 \mathrm{~h}$ with $70 \%$ ethanol. After washing, cells were incubated with RNAse A for $30 \mathrm{~min}$ at $37{ }^{\circ} \mathrm{C}$ and then stained with propidium iodide $(10 \mu \mathrm{g} / \mathrm{ml})$ for additional $30 \mathrm{~min}$ at $37^{\circ} \mathrm{C}$ in the dark. Stained cells were analysed on a FACSCalibur Flow Cytometer (Becton Dickinson, San Josè, CA, USA).

\section{Assay of cell growth}

The cells were seeded at $1-3 \times 10^{4} / \mathrm{ml}$ in $35 \mathrm{~mm}$ dishes. After overnight incubation at $37^{\circ} \mathrm{C}$, PP2 inhibitor was added (or DMSO, as control) and cells were incubated at $37^{\circ} \mathrm{C}$ for $24 \mathrm{~h}$. Viable cells were examined using the trypan blue dye and counted in a Thoma's chamber. Results are mean \pm s.D. of three experiments performed in triplicate.

\section{Adhesion assay}

The assay was performed in $35 \mathrm{~mm}$ dishes. At $37^{\circ} \mathrm{C}$, $10^{3}$ cells were incubated for $30 \mathrm{~min}$ in suspension, with $10 \mu \mathrm{M}$ PP2 or equal volume of DMSO, then were plated and incubated at $37{ }^{\circ} \mathrm{C}$ for the indicated time. Suspended cells were collected by pipetting and rinsing, attached cells were collected by trypsinization. Collected cells were counted in a Thoma's chamber. In the experiments with purified ECM proteins, dishes were pre-coated with $10 \mu \mathrm{g} / \mathrm{ml}$ collagen IV (Chemicon, Temecula, CA, USA), fibronectin (SigmaAldrich), laminin (Sigma-Aldrich) or $0.1 \mu \mathrm{g} / \mathrm{cm}^{2}$ of vitronectin (Sigma-Aldrich) or FBS 10\% (Gibco BRL) or BSA $3 \%$ (Sigma-Aldrich) overnight at $37^{\circ} \mathrm{C}$ or with $0.1 \mathrm{mg} / \mathrm{ml}$ poly-L-lysine for $5 \mathrm{~min}$ at room temperature. After twice brief washes in Sterile Water (endotoxin tested, Sigma-Aldrich), dishes were dried for $1 \mathrm{~h}$ to be used for the adhesion assay. Dishes were then washed twice in PBS and adsorbed with $1 \%$ BSA at $37^{\circ} \mathrm{C}$ for $1 \mathrm{~h}$. After a brief wash in PBS, pre-coated dishes were used for the adhesion assay as described above. Results are mean \pm s.D. of three experiments performed in triplicate.

\section{Scratch wound-healing motility assay}

QGP-1 cells were plated at $60 \%$ of confluence and incubated at $37^{\circ} \mathrm{C}$ until the plate was confluent. The confluent monolayer was incubated for $30 \mathrm{~min}$ at $37^{\circ} \mathrm{C}$ with $10 \mu \mathrm{M}$ PP2 or DMSO before creating a wound by scratching with a sterile pipette tip. The plate was photographed immediately and 16 and $24 \mathrm{~h}$ after scratching.

\section{Immunoprecipitation assay}

QGP-1 cells were plated and incubated at $37^{\circ} \mathrm{C}$ for 75 min with $10 \mu \mathrm{M}$ PP2 or $0.1 \%$ DMSO. Cells were resuspended in lysis buffer $(100 \mathrm{mM} \mathrm{NaCl}, 10 \mathrm{mM}$ $\mathrm{MgCl}_{2}, 30 \mathrm{mM}$ Tris- $\mathrm{HCl}$ (pH 7.5), $1 \mathrm{mM}$ dithiothreitol, $2 \mathrm{mM}$ Na-ortovanadate and protease inhibitor cocktail, (Sigma-Aldrich), supplemented with $1 \%$ Triton X-100) and kept on ice for $10 \mathrm{~min}$. For immunoprecipitation of FAK, lysis buffer was 
supplemented with $0.1 \%$ SDS and $0.5 \%$ Na-deoxycolic acid. Soluble extracts were separated by centrifugation at 12000 r.p.m. for $10 \mathrm{~min}$. Extracts (500-850 $\mu \mathrm{g}$ total proteins) were pre-adsorbed to $1 \mu \mathrm{g}$ mouse or rabbit preimmune IgGs bound to Protein A/G-sepharose beads (Sigma-Aldrich) for $1 \mathrm{~h}$ at $4{ }^{\circ} \mathrm{C}$ under constant shaking. At the end of incubation, supernatants were incubated for $2 \mathrm{~h}$ at $4{ }^{\circ} \mathrm{C}$ under constant shaking with $2 \mu \mathrm{g}$ anti-phosphotyrosine antibody (PY20, Santa Cruz Biotechnology, INC., Santa Cruz, CA SC-508, USA) or $1 \mu \mathrm{g}$ anti-p130Cas (Cell Signalling), or anti-FAK (Cell Signalling) or control IgGs and protein A/Gsepharose beads. All the beads with antibodies were pre-adsorbed with $0.05 \% \mathrm{BSA}$ at $4{ }^{\circ} \mathrm{C}$ under constant shaking, before incubation with the extracts. Immunocomplexes were washed thrice with lysis buffer and adsorbed proteins were eluted in SDS-sample buffer (62.5 mM Tris- $\mathrm{HCl}(\mathrm{pH}$ 6.8), $10 \%$ glycerol, $2 \%$ (wt/vol.) SDS, $0.7 \mathrm{M}$ 2-mercaptoethanol and $0.0025 \%$ (wt/vol.) bromophenol blue) and resolved on a $8 \%$ SDS-PAGE for subsequent Western blot analysis.

\section{Plasmid construction}

The sequence encoding the SH3 domain of Src was amplified by PCR using pCMV5-Src containing the chicken Src sequence (accession number V00402) as template, the Pfu polymerase (Stratagene, La Jolla, CA, USA) and oligonucleotides 5'-AGGGATCCACCACTTCCGTGGCTCTCTACGAC- $3^{\prime}$ (forward) and 5'-AGGGATCCCTCGATGGAGTCTGAGGGCGC$3^{\prime}$ (reverse). The PCR product was subcloned in-frame with glutathione-S-transferase (GST) into the pGEX$4 \mathrm{X} 1$ vector (Pharmacia) into the BamHI site. GST$\mathrm{SrcSH} 2$ has been previously described (Sette et al. 2002). Expression and purification of GST fusion proteins was performed by standard procedures as described previously (Sette et al. 1998).

\section{Pull-down assay}

The cell extracts $(250-300 \mu \mathrm{g})$ were pre-cleared on glutathione-sepharose beads (Sigma-Aldrich) for $1 \mathrm{~h}$ at $4{ }^{\circ} \mathrm{C}$. Pre-cleared cell extracts were then incubated for $2 \mathrm{~h}$ at $4{ }^{\circ} \mathrm{C}$ under constant shaking with glutathione-sepharose beads (Sigma-Aldrich) coated with purified GST, or GST-SrcSH2 or GST-SrcSH3 fusion proteins. Hence, beads were washed thrice with lysis buffer and adsorbed proteins were eluted in SDSsample buffer for Western blot analysis.

\section{Tissue extracts}

Donor islets were purified as previously reported (Capurso et al. 2006). Neuroendocrine tumors (NETs) were snap-frozen immediately after surgical removal from patients. Extracts were prepared by resuspending the samples in $500 \mu$ lysis buffer (see above) and homogenized with a Dounce glass homogenator. After clarification of the extracts by centrifugation (12000 r.p.m. for $10 \mathrm{~min}$ at $4{ }^{\circ} \mathrm{C}$ ), soluble extracts were analysed for protein concentration by standard methods (Sette et al. 2002) and diluted in SDS-sample buffer before using them for Western blot analysis.

\section{Western blot analysis}

Cell extracts or immunoprecipitated proteins were diluted in SDS-sample buffer and boiled for $5 \mathrm{~min}$. Proteins were separated on either 10 or $8 \%$ SDS-PAGE gels and transferred to PVDF Transfer Membrane Hybond-P (Amersham Bioscience). Membranes were saturated with 5\% non-fat dry milk in PBS containing $0.1 \%$ Tween 20 , or with TBS containing $0.1 \%$ Tween 20 and 5\% BSA for $1 \mathrm{~h}$ at room temperature, and incubated with the following primary antibody: mouse $\alpha$-tubulin (1:1000, Sigma-Aldrich), rabbit $\alpha$-actin (1:1000, Sigma-Aldrich), rabbit $\alpha$-ERK2 (1:1000, SantaCruz Biotechnology), mouse $\alpha$-v-Src (1:500, Oncogene, Research Products, Calbiochem, Ab-1), rabbit $\alpha$-Fyn (1:1000, SantaCruz Biotechnology), rabbit $\alpha$-Lck $(1: 1000$, Cell Signalling) rabbit, rabbit $\alpha$-FAK (1:1000, Cell Signalling), mouse $\alpha$-p130Cas (1:1000, BD Transduction Laboratories, Lexington, KY, USA), mouse $\alpha$-phosphotyrosine (PY20, 1:1000, SantaCruz Biotechnology), rabbit anti-pSrc418 (1:1000, Biosource, Calmarillo, CA, USA). Secondary $\alpha$-mouse or $\alpha$-rabbit IgGs conjugated to horseradish peroxidase (Amersham) were incubated with the membranes for $1 \mathrm{~h}$ at room temperature, at a 1:10 000 dilution in PBS or TBS containing $0.1 \%$ Tween 20. Immunostained bands were detected by chemiluminescent method (SantaCruz Biotechnology).

\section{Immunofluorescence analysis}

QGP-1 cells were fixed for $10 \mathrm{~min}$ in $4 \%$ paraformaldehyde, permeabilized with $0.1 \%$ Triton X-100 and processed for immunofluorescence analysis using $\alpha$-phalloidin antibody (1:200, Sigma-Aldrich) or $\alpha$-p130Cas (1:100, BD Tranduction Laboratories) antibody and Hoechst DNA staining. Cy3-conjugate anti-mouse secondary antibody (1:300, Chemicon) was used to detect p130Cas localization. 


\section{Results}

\section{Expression of Src family kinases in pancreatic endocrine cancer cells}

To investigate the expression and the function of $\mathrm{Src}$ family kinases in PET cells, we have used two cell lines that were originated from metastatic insulinoma $(\mathrm{CM}$ cells) and somatostatinoma (QGP-1). These cell lines have been previously shown to maintain some characteristics of the original tumours (Iguchi et al. 1990, Baroni et al. 1999). Western blot analyses with antibodies specific for Src, Fyn and Lck, three of the more commonly activated Src family kinases in cancer (Irby \& Yeatman 2000), indicated that all three isoforms were expressed. Src was the most readily detected by this technique in CM and QGP-1 cells, followed by Fyn and Lck (Fig. 1A). To determine the relative activity of Src in these PET cell lines, we analysed cell extracts from QGP-1 and CM cells with an antibody that
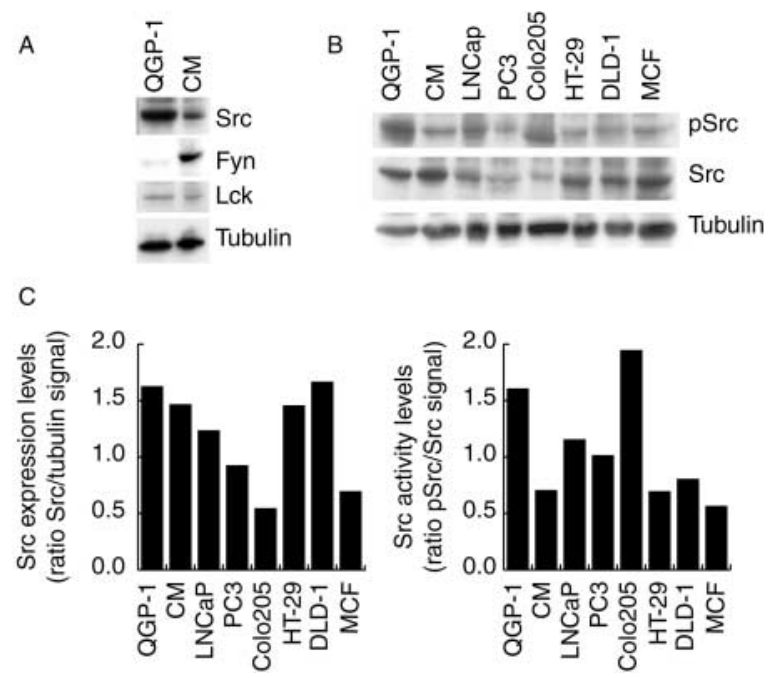

Figure 1 Elevated expression and activity of Src family kinases in QGP-1 cells. (A) Western blot analysis of the expression of the Src family kinases Src, Fyn and Lck in QGP-1 and CM cell lines. Src expression is higher in QGP-1 than CM cells, whereas Fyn expression is higher in CM than QGP-1. Lck is expressed in equal amount in both of the two PET cell lines at lower levels than the other two kinases analysed. Tubulin staining demonstrates equal loading of the samples. (B) Western blot analysis of PET cell lines (QGP-1 and CM) and of other cancer cell lines. Upper panel shows activated phospho-Src levels stained with an antibody that recognize Src phosphorylated on tyrosine 416; middle panel shows total Src levels; lower panel shows tubulin expression for the quantitative analyses. (C) Densitometric analyses (average of two experiments) of Src expression levels obtained by ratio between total Src versus tubulin signal (left panel) or of relative Src kinase activity by ratio between phospho-Src versus total Src signal (right panel). QGP-1 and CM cells display high Src expression levels comparable with the colon cancer cell lines HT-29 and DLD-1. QGP-1 displays higher Src activity than CM cells. Src activity in QGP-1 cells was similar to that in Colo205, a colon cancer cell line that express activated Src. recognizes the active form of Src (phosphorylated on tyrosine 416; anti-pSrc) and compared it with that of cancer cell lines of different origins. We observed that QGP-1 cells display very high levels of Src activity, as elevated as that of Colo205 (Fig. 1B), a colon cancer cell line that is frequently used to study the role of up-regulation of Src in cancer cells (Golas et al. 2005). Although lower than in QGP-1, the activity of Src in CM cells was comparable with that of MCF-7, a breast cancer cell line in which Src is required for cell proliferation and invasiveness (Castoria et al. 2001). Quantitative densitometric analyses of Src expression level and activity are reported in Fig. 1C and represent the mean of two separate experiments.

Next, we analysed the expression of Src in human PETs by immunohistochemistry. In the healthy pancreas, Src immunoreactivity was detected as a moderate cytosolic staining in cells of islets of three different patients not affected by PETs, with some peripheral cells showing stronger staining. Surrounding acinar cells were less intensively labelled than islet cells (Fig. 2A). In PETs, Src staining was positive in all of the 27 samples examined, with a mean score of 10.6 (95\% CI 9.7-11.4; Table 1). The immunoreactivity was diffusely cytoplasmic, with some membrane reinforcement (Fig. 2B) and with a clearly stronger intensity and diffusion when compared with that seen in normal islet cells (Fig. 2B-D).

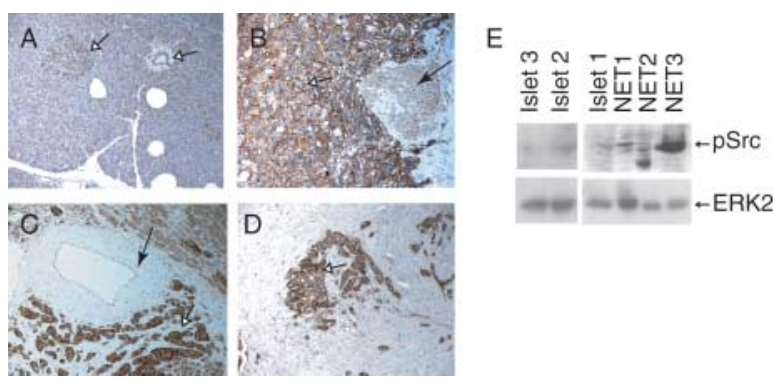

Figure 2 Immunohistochemical analysis of Src expression in pancreatic endocrine tumours. (A) Src staining in a section of normal pancreas. Islet cells and a pancreatic duct, indicated by a white arrow in the top left and right top corners respectively, show a moderate cytoplasmic immunoreactivity. Acinar cells show a less intense cytoplasmic immunoreactivity. (B) Pancreatic WDEC with perineural invasion. The nerve structure (black arrow) shows very weak Src immunoreactivity. The tumour cells (in the area of the white arrow) show both membrane and cytoplasmic staining. (C) WDEC forming trabecular aggregates shows strong Src staining (white arrow). Perivascular invasion is visible (black arrow) with the vessel negative for Src. Expression of Src is also observed in a case of liver metastasis from a pancreatic WDEC, shown in panel (D). Similar cytoplasmic and membrane reactivity is shown (white arrow), with no staining in the surrounding stroma. (E) Western blot analysis with the anti-active pSrc antibody of cell extracts $(30 \mu \mathrm{g})$ obtained from three purified donor islets or from WDEC liver metastasis (NET1) or primitive PDEC (NET2) or PDEC liver metastasis (NET3). 
Table 1 Src immunoreactivity in PETs

\begin{tabular}{|c|c|c|c|c|c|c|c|c|c|c|c|c|c|}
\hline Patient & Sex & Age & $\begin{array}{c}\text { Functional } \\
\text { status }^{a}\end{array}$ & $\begin{array}{c}\text { WHO } \\
\text { diagnosis }^{b}\end{array}$ & Site ${ }^{c}$ & $\mathbf{G a}^{\mathrm{d}}$ & $\mathbf{G I}^{\mathrm{d}}$ & $\ln \mathbf{s}^{d}$ & $\mathbf{P P}^{\mathrm{d}}$ & Chr-A $^{\mathrm{e}}(\%)$ & $\operatorname{Syn}^{\mathrm{e}}(\%)$ & Ki-67 (\%) & $\begin{array}{l}\text { Src score }(0-12 \\
\text { intensity } \times \text { extent })\end{array}$ \\
\hline 1 & $\mathrm{~F}$ & 37 & NF & WDEC & NM & - & - & - & + & 100 & 100 & 10 & 9 \\
\hline 2 & $\mathrm{~F}$ & 57 & NF & WDEC & $P$ & - & - & - & - & 100 & 100 & 1 & 12 \\
\hline Matched & $\mathrm{F}$ & 57 & NF & WDEC & LM & - & - & - & - & 100 & 100 & 2 & 9 \\
\hline 3 & $\mathrm{~F}$ & 49 & NF & WDEC & LM & - & - & - & - & 0 & 5 & 30 & 9 \\
\hline 4 & $\mathrm{~F}$ & 45 & NF & WDEC & $\mathrm{P}$ & - & - & + & - & 100 & 100 & 2 & 12 \\
\hline 5 & $\mathrm{~F}$ & 61 & NF & WDEC & LM & - & - & - & - & 100 & 100 & 4 & 12 \\
\hline 6 & $\mathrm{M}$ & 60 & NF & WDEC & $\mathrm{P}$ & + & + & - & + & 100 & 100 & 9 & 12 \\
\hline 7 & $\mathrm{~F}$ & 67 & NF & WDEC & $\mathrm{P}$ & + & - & - & - & 20 & 100 & 5 & 12 \\
\hline 8 & $M$ & 45 & NF & WDEC & LM & - & - & - & - & 100 & 100 & 15 & 12 \\
\hline 9 & $\mathrm{~F}$ & 39 & NF & PDEC & NM & - & + & - & - & 50 & 100 & 10 & 6 \\
\hline 10 & $M$ & 66 & NF & WDEC & $\mathrm{P}$ & - & - & + & + & 2 & 100 & 5 & 12 \\
\hline 11 & $\mathrm{~F}$ & 51 & NF & WDEC & $\mathrm{P}$ & - & + & - & + & 50 & 100 & 4 & 8 \\
\hline 12 & $\mathrm{M}$ & 69 & NF & PDEC & LM & - & - & - & - & 100 & 100 & 11 & 6 \\
\hline 13 & $\mathrm{~F}$ & 55 & NF & WDEC & $\mathrm{P}$ & - & - & - & - & 100 & 100 & 3 & 12 \\
\hline 14 & $\mathrm{~F}$ & 60 & NF & WDET & $\mathrm{P}$ & - & - & - & - & 100 & 100 & $<1$ & 12 \\
\hline 15 & $\mathrm{M}$ & 65 & NF & WDEC & LM & - & - & - & - & 70 & 100 & 3 & 4 \\
\hline 16 & $F$ & 63 & NF & WDEC & $P$ & - & - & - & - & 80 & 100 & 30 & 12 \\
\hline Matched & $\mathrm{F}$ & 63 & NF & WDEC & LM & - & - & - & - & 70 & 100 & 30 & 9 \\
\hline 17 & $F$ & 20 & NF in MEN-I & WDET & $\mathrm{P}$ & - & + & - & + & 100 & 100 & 1 & 12 \\
\hline 18 & $\mathrm{~F}$ & 70 & Insulinoma & WDET & $\mathrm{P}$ & - & - & + & - & 100 & 100 & 3 & 12 \\
\hline 19 & $\mathrm{~F}$ & 64 & Insulinoma & WDET & $\mathrm{P}$ & - & - & + & - & 100 & 100 & $<1$ & 12 \\
\hline 20 & $\mathrm{M}$ & 78 & NF & WDEC & $\mathrm{P}$ & - & + & - & - & 60 & 100 & 8 & 12 \\
\hline 21 & $\mathrm{~F}$ & 71 & Insulinoma & WDET & $\mathrm{P}$ & - & - & + & - & 100 & 100 & 3 & 12 \\
\hline 22 & $\mathrm{~F}$ & 63 & Insulinoma & WDET & $\mathrm{P}$ & + & - & + & + & 100 & 100 & $<1$ & 12 \\
\hline 23 & $\mathrm{~F}$ & 58 & NF & WDEC & $\mathrm{P}$ & - & - & - & - & 70 & 100 & 5 & 12 \\
\hline Matched & $\mathrm{F}$ & 58 & NF & WDEC & LM & - & - & - & - & 70 & 100 & 7 & 12 \\
\hline 24 & M & 52 & NF & WDEC & $\mathrm{P}$ & + & - & - & + & 100 & 100 & 2 & 12 \\
\hline
\end{tabular}

Clinical and histopathological features, the immunoreactivity for gastrointestinal hormones, neuroendocrine markers and Ki67 proliferation marker are also detailed.

${ }^{a} \mathrm{NF}$, non-functioning, indicates the absence of a clinical syndrome.

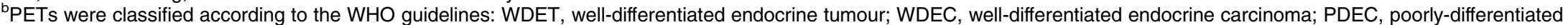
endocrine carcinoma.

${ }^{\mathrm{C} P}$, primary; NM, node metastasis; LM, liver metastasis.

${ }^{\mathrm{d}} \mathrm{Ga}$, gastrin; Gl, glucagon; Ins, insulin; PP, pancreatic polypeptide.

${ }^{\mathrm{e}} \mathrm{Chr}-\mathrm{A}$, chromogranin A; Syn, synaptophysin. 
Src immunoreactivity in primary lesions, mean score 11.7 (95\% CI 11.3-12.2), was significantly higher than that in metastatic samples, mean score 8.5 (95\% CI 6.6$10.3 ; P<0.0001)$. In the three cases for which we were able to analyse both primary and matched metastatic lesion, immunoreactivity was higher in the primary lesion in two patients and equal in the third. Moreover, Src immunoreactivity seemed stronger in WDETs (mean score 12) than in WDECs (mean score 10.5) and PDECs (mean score 6), albeit without a significant difference. To determine the activity of Src in islet cells and PETs, we performed Western blot analyses with the anti-pSrc antibody on cell extracts obtained from three purified fractions of normal islet cells or from PET lesions (one primary tumour and two liver metastases). As shown in Fig. 2E, Src activity was elevated in neoplastic tissues when compared with normal islets. These data indicate that Src expression and activity are elevated in human PETs.

\section{Inhibition of Src family kinase activity does not affect cell cycle progression of PET cells}

To investigate the role of Src family kinases in PET cells, we inhibited the catalytic activity using the specific inhibitor PP2 (Hanket et al. 1996; Fig. 3A).
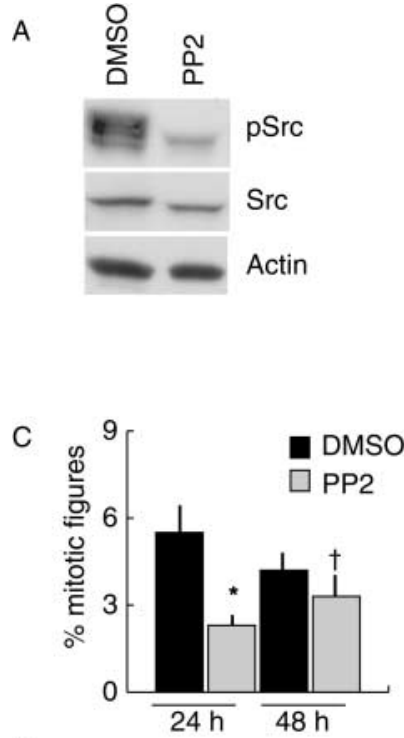

E

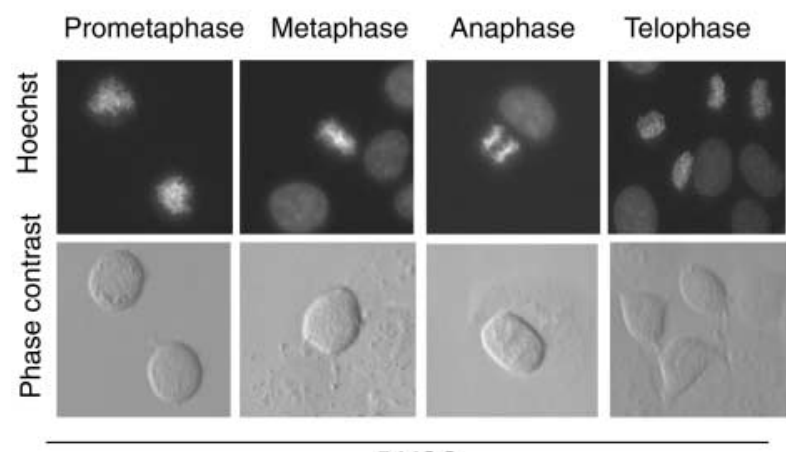

DMSO
B

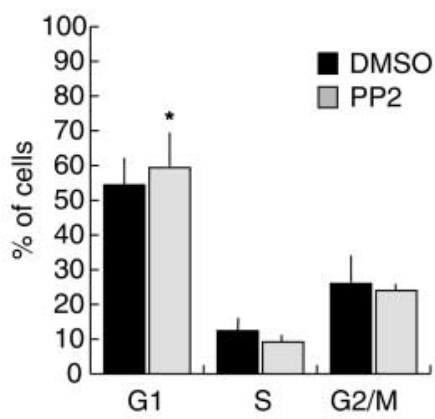

D

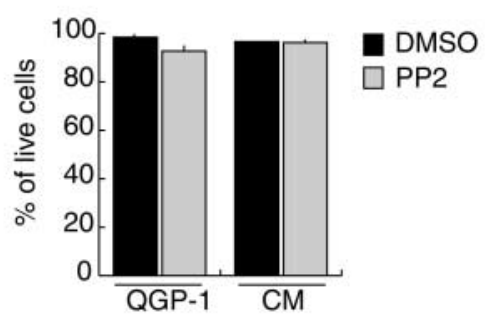

Metaphase Anaphase

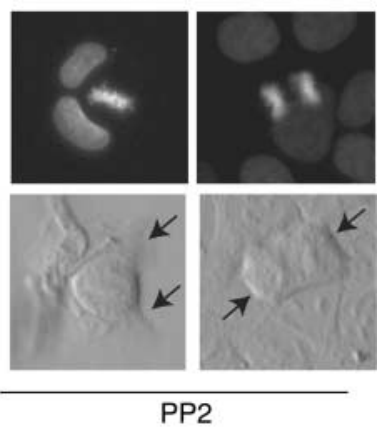

Figure 3 Inhibition of Src family kinases activity does not interfere with QGP-1 and CM cell cycle progression. (A) Western blot analyses of QGP-1 cells incubated with PP2 or DMSO (as control) for $24 \mathrm{~h}$ stained with $\alpha$-Src and $\alpha$-pSrc antibodies to test the inhibition of Src family activity by PP2 and $\alpha$-actin to show equal loading. (B) QGP-1 cells were treated with the Src family kinases inhibitor PP2 $(10 \mu \mathrm{M})$ for $24 \mathrm{~h}$ and cell cycle progression was analysed by FACS as described in the Materials and methods. PP2 causes a transient delay of cell cycle in G1 when compared with untreated cells (DMSO; ${ }^{\star} P<0.05$ ). (C) Treatment of QGP-1 for $24 \mathrm{~h}$ with PP2 inhibitor transiently reduced the number of mitotic figures (prometaphase, metaphase and anaphase). The reduction was diminished after 48-h incubation ( ${ }^{*} P<0.01$ and ${ }^{\dagger} P<0.05$ as determined by Student's $t$-test). (D) Cell survival was analysed by Trypan blue staining in QGP-1 and CM cells treated with or without PP2 inhibitor for $24 \mathrm{~h}$. The inhibition of Src kinases activity does not reduce cell survival. (E) Hoechst staining and phase images of prometaphase, metaphase, anaphase and telophase QGP-1 cells and metaphase and anaphase of QGP-1 cells treated with PP2 for $24 \mathrm{~h}$. Inhibition of Src kinases activity reduces the ability of QGP-1 cells to become round and detach from the plate at mitosis, as shown by black arrows. 
The effect of prolonged inhibition of Src family activity on cell cycle progression in QGP-1 cells was tested by FACS analysis of DNA content after 24-48-h incubation. We observed that PP2 caused a slight accumulation of cells in G1 after $24 \mathrm{~h}$ (Fig. 3B) and a decrease in mitotic figures (Fig. 3C). However, cell cycle retardation was transient and $48 \mathrm{~h}$ after plating the effect of Src inhibition on mitotic figures (Fig. 3C) and on accumulation in G1 (data not shown) was almost negligible. Similar results were obtained with CM cells (data not shown). Moreover, treatment with PP2 did not affect cell survival in both QGP-1 and CM cells, as determined by trypan blue staining (Fig. 3D) and TUNEL assay (data not shown). Interestingly, we observed that PP2 interfered with cell rounding in mitosis, indicating that inhibition of Src caused a defective reorganization of the cytoskeleton and may cause a retarded progression through mitosis (Fig. 3E).
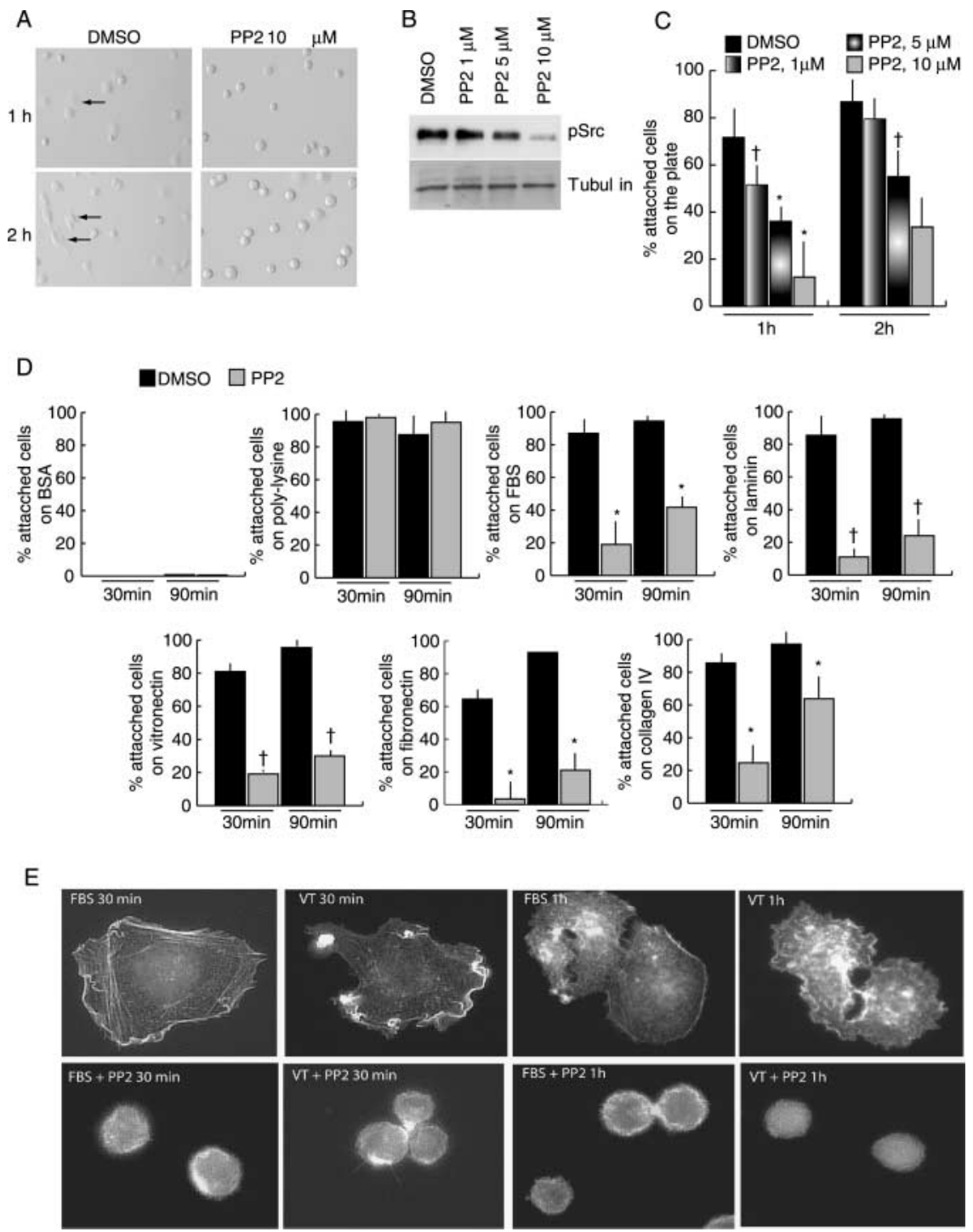

Figure 4 Inhibition of Src family kinases activity interferes with cell adhesion and spreading. (A) Phase contrast images of QGP-1 cells pre-incubated for $30 \mathrm{~min}$ in the presence of $10 \mu \mathrm{M}$ PP2 inhibitor or DMSO and then plated on tissue culture dishes for 1 and $2 \mathrm{~h}$ at $37^{\circ} \mathrm{C}$. After $2 \mathrm{~h}$, untreated cells (DMSO) were almost all attached, as demonstrated by their flat and spread shape (black arrows). PP2-treated cells remained with a round shape loosely attached to the plate even after $3 \mathrm{~h}$. (B) Western blot analysis with anti-pSrc of QGP-1 extracts treated with 1, 5 or $10 \mu \mathrm{M}$ PP2. (C) Adhesion assay of QGP-1 performed using 1, 5 or $10 \mu \mathrm{M}$ PP2. (D) Adhesion assays of QGP-1 on plates pre-coated with laminin, vitronectin, fibronectin, collagen IV, FBS, poly-L-lysine or BSA in the presence or absence of $10 \mu \mathrm{M}$ PP2 $\left({ }^{\star} P<0.02\right.$ and ${ }^{\dagger} P<0.05$; as determined by the Student's $t$-test). (E) Immunofluorescence analysis of the actin cytoskeleton by phalloidin staining of QGP-1 cells seeded on serum- or vitronectin-coated plates in the presence or absence of $10 \mu \mathrm{M}$ PP2. 


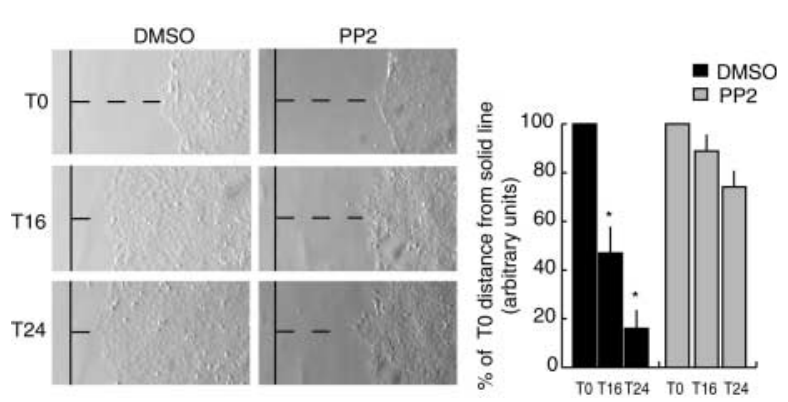

Figure 5 Inhibition of Src family kinases activity reduces the ability of QGP-1 cells to migrate. Wounds were made using a sterile pipette in a plate with confluent QGP-1 cells that were pretreated for 30 min with $10 \mu \mathrm{M}$ PP2 or DMSO. Plates were photographed at the indicated time after the wound was produced. Incubation with PP2 strongly reduces the migration of QGP-1 cells. This reduced ability to migrate was quantified evaluating the distance of the cells front from the solid line, which was associated to an internal mark. Panel on the right reports the results of three separate experiment (mean \pm s.D.) indicated as percentage of the T0 distance from the line.

\section{Src family kinase activity is required for adhesion, spreading and migration of PET cells}

To investigate whether Src kinases play a role in the reorganization of the cytoskeleton, we measured adhesion of PET cells in the presence of the PP2 inhibitor. In the absence of inhibitors, approximately $70 \%$ of QGP-1 cells attached to the plate within $1 \mathrm{~h}$ and $90 \%$ were attached $2 \mathrm{~h}$ after plating, as evident from the flat shape of the attached cells (Fig. 4A, black arrows). Treatment with PP2 caused a dose-dependent inhibition of Src (Fig. 4B) that correlated with reduction in the number of cells attached, which remained with a rounded shape loosely bound to the plate even after $2 \mathrm{~h}$ (Fig. 4C). The effect of PP2 was more dramatic in QGP-1 cells, which display higher levels of Src activity (Fig. 1B), than in CM cells (data not shown).

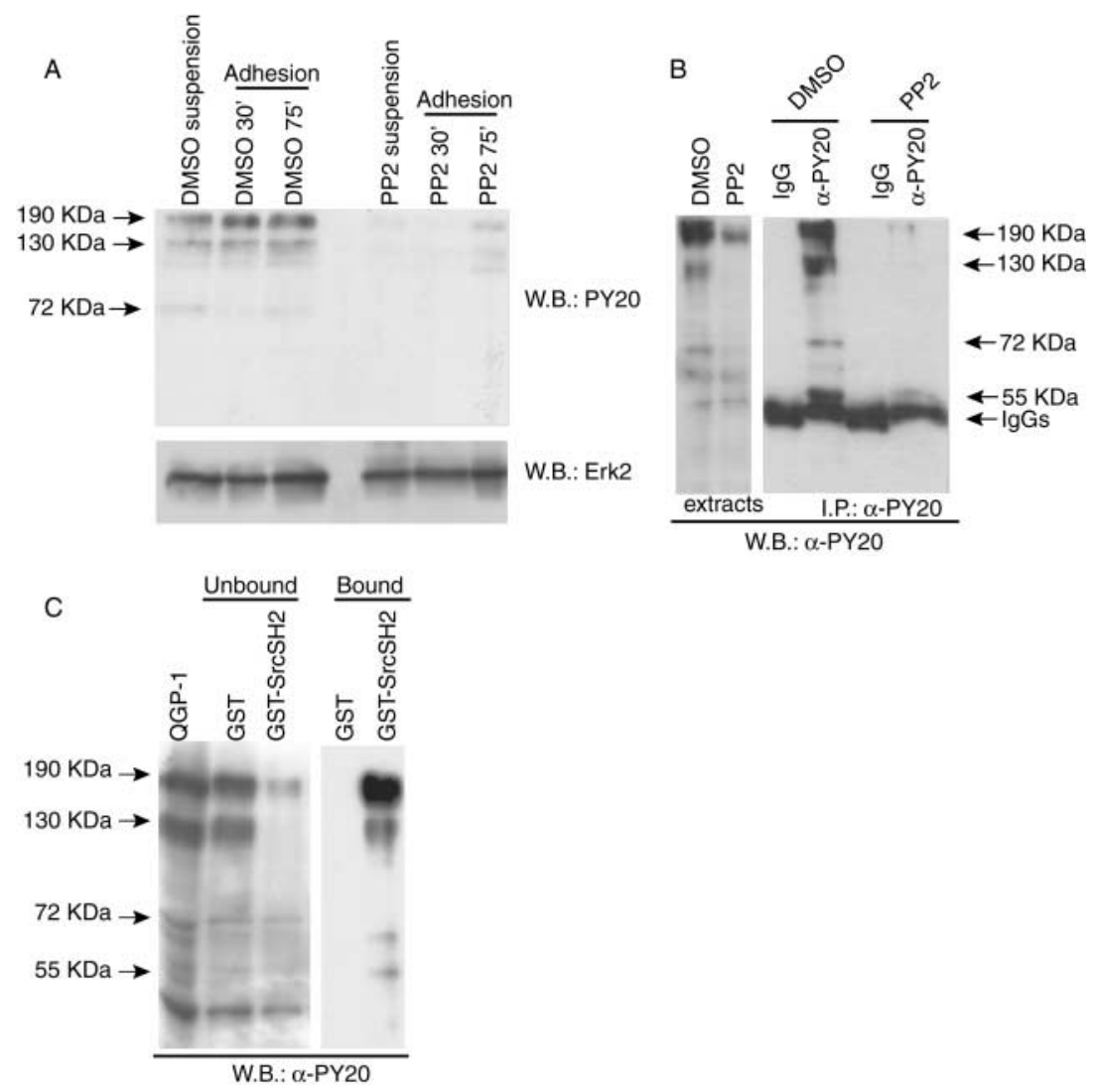

Figure 6 Inhibition of Src family kinases activity reduces tyrosine phosphorylation of substrates involved in QGP-1 adhesion process. (A) Western blot with the anti-phosphotyrosine antibody ( $\alpha$-PY20) of cell extracts of QGP-1 cells in suspension or harvested 30 or 75 min after seeding in complete medium supplemented with either DMSO $10 \mu \mathrm{M}$ PP2. Tyrosine phosphorylation of two polypeptide bands, p190 and p130 are increased in a Src-dependent manner during adhesion. (B) Anti-phosphotyrosine immunoprecipitation of extracts from QGP-1 harvested 75 min after seeding in the presence or absence of PP2 (left panel). The right panel shows that four tyrosine phosphorylated proteins are immunoprecipitated with $\alpha$-PY20 antibody (p190, p130, p72 and p55) in a Src kinases activity-dependent manner. (C) Pull-down assay with GST-Src SH2 fusion protein or control GST from cells incubated for 75 min after seeding; the phosphorylated molecules involved in QGP-1 adhesion were bound by the $\mathrm{SrcSH} 2$ domain and they were depleted from the extracts recovered after the pull-down assay (unbound). 


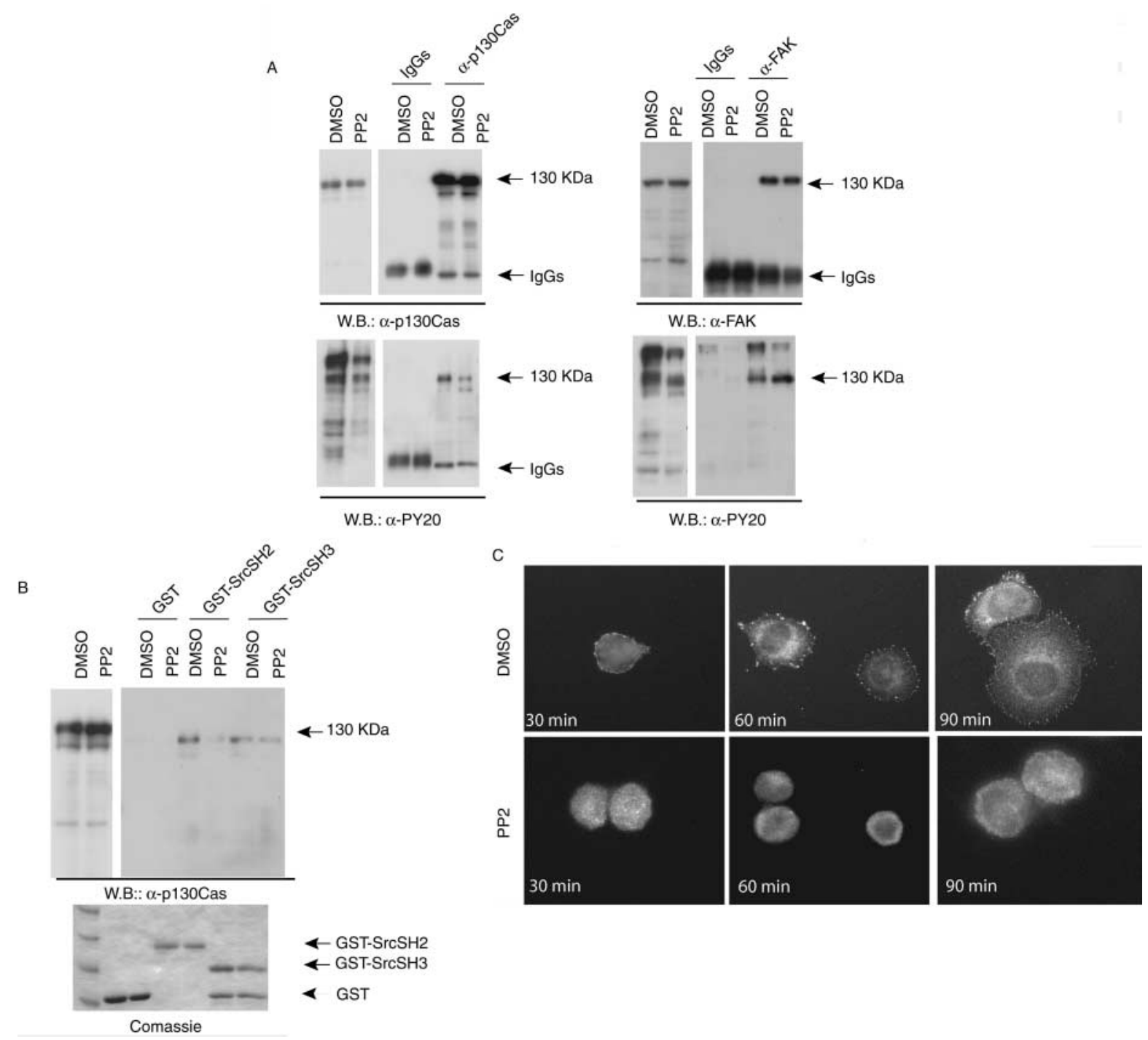

Figure 7 p130Cas, but not FAK, is modulated by Src kinases during adhesion of QGP-1 cells. (A) Western blot analysis of $p 130 \mathrm{Cas}$ and FAK in QGP-1 cells. Cell extracts from QGP-1 collected 75 min after seeding in the presence of either DMSO or $10 \mu M$ PP2 were immunoprecipitated with $\alpha$-p130Cas (left panel) or $\alpha$-FAK (right panel) antibodies. Samples were stained with either $\alpha$-p130Cas and $\alpha$-PY20 (left panels) or $\alpha$-FAK and $\alpha$-PY20 (right panels) as indicated in the figure text. PP2 treatment decreased tyrosine phosphorylation of p130Cas, but not of FAK. (B) Pull-down assay using control GST or GST-SrcSH2, or GST-SrcSH3 fusion proteins from cells incubated for 75 min after seeding in the presence of DMSO or $10 \mu \mathrm{M}$ PP2. p130Cas binds to both the SH2 and the SH3 domains of Src but PP2 treatment interferes only with SH2 binding. (C) Immunofluorescence analysis of p130Cas in QGP-1 cells seeded in the presence of DMSO (upper panels) or $10 \mu \mathrm{M}$ PP2 (lower panels). Inhibition of Src kinases activity impairs membrane localization of $\mathrm{p} 130 \mathrm{Cas}$ during adhesion.

To define in more detail the effect of Src family kinases inhibition on adhesion of QGP-1 cells, we performed assays on different ECM protein substrates. Plates were pre-coated with purified laminin, vitronectin, fibronectin or collagen IV; BSA and FBS were used as negative and positive control respectively. The cells were plated in the presence or absence of PP2 and adhesion was measured after 30 or $90 \mathrm{~min}$. QGP-1 cells attached to FBS, laminin, vitronectin, collagen IV and fibronectin, but not to BSA. Inhibition of Src activity transiently impaired adhesion on FBS and collagen IV, whereas the effect on laminin, fibronectin and vitronectin lasted longer (Fig. 4D). Non-integrinmediated adhesion to poly-L-lysine-coated plates was unaffected by PP2 (Fig. 4D). Inhibition of Src kinases completely blocked also the spreading of attached cells 
on FBS- or vitronectin-coated plates, as shown by the impairment of the actin cytoskeleton and the round shape of the cells treated with PP2 (Fig. 4E).

To determine the role of Src family kinases in migration of QGP-1 cells, we performed a woundhealing assay in the presence or absence of PP2. As shown in Fig. 5, QGP-1 was capable to migrate and colonize the wounded region of the plate within 16-24 h. However, PP2 strongly impaired this process indicating that Src family activity is also required for their migration.

\section{Phosphorylation of selected substrates by Src family kinases during adhesion of QGP-1 cells}

Given the role of Src activity in adhesion, spreading and motility of QGP-1 cells, we searched for potential molecular targets. As a first approach, we determined if some proteins were phosphorylated in a Src kinasesdependent manner during adhesion. Cell extracts from QGP-1 cells in suspension displayed only weak tyrosine-phosphorylated bands. On the other hand, two tyrosine-phosphorylated bands of approximately 130 and $190 \mathrm{kDa}$ were increased 30 or $75 \mathrm{~min}$ after the cells were seeded in the plate (Fig. 6A). Treatment with PP2 during this process strongly affected phosphorylation of these two proteins, indicating that their phosphorylation was dependent on Src kinases activity (Fig. 6A). To isolate and characterize these proteins, we performed an immunoprecipitation experiment using the anti-phosphotyrosine antibody PY20. Western blot analysis of proteins immunoprecipitated showed four major tyrosinephosphorylated bands: p190, p130, p72 and p55 (Fig. 6B). All these phosphorylations were strongly affected by addition of PP2 during adhesion, confirming that their phosphorylation was mediated by Src kinases.

Src kinases interact with several substrates through their SH2 domains. To determine if p190, p130, p72 and p55 could bind Src, we performed a pull-down assay of QGP-1 cell extracts with a GST-SrcSH2-purified protein adsorbed to glutathione-agarose beads. As shown in Fig. 6C, all phosphoproteins were efficiently depleted from the extracts (unbound) and bound to GST-SrcSH2 beads but not to GST beads, indicating that they can interact with this domain of Src.

The docking protein p130Cas and the tyrosine kinase FAK are known substrates of Src and Fyn that are involved in remodelling of the actin cytoskeleton. To determine whether these proteins were substrates of Src kinases, QGP-1 cells were collected 75 min after seeding in the presence or absence of PP2 and extracts were immunoprecipitated with either control IgGs or anti-p130Cas or anti-FAK antibodies (Fig. 7A). Tyrosine phosphorylation was detected by Western blot with the PY20 antibody. Both p130Cas and FAK were strongly phosphorylated during adhesion of QGP1 cells; however, Src family activity was required only for phosphorylation of p130Cas. By contrast, phosphorylation of FAK was even increased in cells treated with PP2, indicating that this protein is not substrate of Src kinases under these conditions.

To determine if phosphorylated p130Cas bound to Src in QGP-1 cells, we performed pull-down assays using purified GST-SrcSH2 or GST-SrcSH3 proteins. We found that p130Cas bound to both $\mathrm{SH} 2$ and $\mathrm{SH} 3$ domain of Src; however, only the interaction with the SH2 domain was inhibited when Src activity was blocked by PP2. This result suggests that p130Cas binds to Src through the $\mathrm{SH} 3$ domain and that it is phosphorylated by the kinase upon its activation during the adhesion process. Finally, immunofluorescence analysis showed that p130Cas readily re-localized from the cytoplasm to the plasma membrane during adhesion, concentrating in discrete sites near the peripheral ruffles, in control QGP-1 cells (Fig. 7C). Inhibition of Src family activity completely blocked the re-localization of p130Cas, confirming that this protein is modulated by Src kinases during adhesion of QGP-1 cells.

\section{Discussion}

PETs are rare neoplastic diseases that are nonresponsive to standard chemotherapeutic approaches. Due to their rare nature, no much information is available on the pathways aberrantly activated in these tumour cells, thereby limiting the possibility to use a targeted therapeutic approach. Our laboratory has recently demonstrated a number of genes up-regulated at the mRNA level in primary and metastatic PETs (Capurso et al. 2006). Among the genes activated, we have confirmed the up-regulation of the Src family kinase Lck at the protein level by immunohistochemistry in approximately $50 \%$ of the samples examined (Capurso et al. 2006). No data on the expression and function of other Src family kinases in PETs are available to date. Thus, we set out to address this study using two available models of PETs: the cell lines QGP-1 and CM. Analyses by Western blot indicated that Src, Fyn and Lck are all expressed in PET cell lines. Src appeared to be the predominant isoform in QGP-1, whereas Fyn was more abundant in CM cells. QGP-1 show high levels of Src family activity in comparison with several cancer cell lines of different origins. Interestingly, Src activity in QGP-1 was 
comparable with Colo205, a colon cancer cell line frequently used for studies on the role of Src in neoplastic cells (Golas et al. 2005).

Since Src was strongly expressed and active in both QGP-1 and CM cells, we investigated its expression also in human PET samples by immunohistochemistry and Western blot. Our results indicate that Src, whose expression is low in normal islet cells, is strongly up-regulated in PETs, with positive staining in $100 \%$ of the samples. Moreover, Western blot analysis with the anti-pSrc antibody showed that the activity of the kinase is increased in the three PET samples examined compared with purified donor islets. Src is the family member most commonly up-regulated in cancer (Irby \& Yeatman 2000) and it was suggested that it might be required in the initial phases of neoplastic transformation, whereas its function is substituted when the cancer cells become poorly differentiated (Weber et al. 1992). Our results in human PETs are in line with this hypothesis and suggest that the amount of Src protein is higher in primary lesions than in metastases.

The main defect caused by inhibition of Src family activity in PET cells was seen on cytoskeletal structures and organization. First of all, PP2 treatment caused a marked delay in QGP-1 and CM cell adhesion. The effect was more pronounced in QGP-1 cells, which express higher Src activity, than CM cells. The delay in adhesion was overcome after $4-5 \mathrm{~h}$ from seeding, indicating that although Src kinases were inactive, PET cells are able to use other less efficient pathways to adhere. Src activity was required for adhesion on several extracellular matrices, particularly on fibronectin, vitronectin and laminin, indicating its crucial role in several adhesion pathways. Interestingly, both fibronectin (Maitra et al. 2003, Capurso et al. 2006) and vitronectin (Hansel et al. 2004) are up-regulated in PETs and gene ontology analyses suggest that several genes for ECM constituents are aberrantly regulated in PETs, highlighting the possible role of cancer-stroma crosstalk in this cancer type (Capurso et al. 2006).

Although Src activity is involved in cell proliferation (Irby \& Yeatman 2000), we found that its inhibition in QGP-1 cells does not interfere with their proliferation and survival. The reduced number of mitotic figures found $24 \mathrm{~h}$ after seeding QGP-1 cells in the presence of PP2 was already attenuated after 48-h treatment. Since the cells grown in PP2 were incompletely detached from the plate in mitosis, we hypothesized that the initial delay in cell divisions was due to altered cytoskeletal dynamics in the absence of Src activity, which may limit the initial attachment to the plate and delay the consequent onset of cell cycle progression.
Alterations in the expression or regulation of proteins involved in actin cytoskeleton turnover are often observed in cancer cells and contribute to their migration and invasiveness (Cavallaro \& Christofori 2004). Focal adhesions, the sites where the actin cytoskeleton is linked to the ECM by integrin/receptor complexes, contribute to cell anchorage and to the recruitment of signalling complexes that are involved in a broad range of cellular processes, including migration, proliferation, transformation and apoptosis. Remarkably, Src family kinases have been reported to act downstream of the modifications of the integrin/ ECM complexes that contribute to neoplastic transformation (O'Neill et al. 2000, McLean et al. 2003, Cabodi et al. 2006). Although the role of adhesion molecules is also recognized in endocrine cancer cells (Ezzat \& Asa 2005), no data are currently available in PETs. Herein, we have demonstrated that QGP-1 cells attached to the plates in the presence of PP2 were not capable to spread on the surface and could not reorganize the actin filaments when compared with control cells. In addition, wound-healing assays showed that Src activity was required also for migration of QGP-1, indicating a role of these kinases also in the actin cytoskeleton turnover. Our results suggest that pharmacological inhibition of Src family kinases might be useful to control the invasiveness of PET cells.

Cell adhesion, spreading and motility use common signalling pathways and many of the proteins involved in these pathways are substrates of Src. We observed that several proteins are phosphorylated in a Srcdependent manner during QGP-1 adhesion. In particular, we identified four proteins of apparent molecular weight of $190,130,72$ and $55 \mathrm{kDa}$ that were reproducibly phosphorylated by $\mathrm{Src}$ in these cells. Interestingly, $130 \mathrm{kDa}$ is the molecular weight of two known substrate of Src strongly involved in adhesion, spreading and motility: p130Cas and the tyrosine kinase FAK (Hanks et al. 1992, O'Neill et al. 2000, Bouton et al. 2001). Immunoprecipitation and pulldown experiments demonstrate that p130Cas interacts with Src and it is phosphorylated by the kinase during the adhesion process of QGP-1. Cas plays a role as scaffold in the actin turnover pathway (Playford \& Schaller 2004) and its involvement in neoplastic transformation of breast epithelial cells (Cabodi et al. 2006) and lymphoma cells (Ambrogio et al. 2005) has been reported. Our results suggest that p130Cas may also be involved in the physiology of PET cells.

Surprisingly, we found that tyrosine phosphorylation of FAK was independent of Src activity in QGP-1 cells. FAK was strongly phosphorylated during adhesion even in the presence of PP2, and its activity may account 
for the ability of PET cells to slowly attach to the ECM even in the absence of Src activity. A similar Srcindependent regulation of FAK has been recently reported in colon carcinoma cells (Brunton et al. 2005), suggesting that QGP-1 is not unique in the regulation of this adhesion pathway. Although the nature of p190, p72 and p55 is still unknown, their molecular weights correspond to those of molecules involved in actin cytoskeleton like RhoGAP (p190), paxillin (p72) or Src kinases themselves (p55).

The results presented herein show for the first time the requirement of Src activity in PET cell adhesion, spreading and migration in culture conditions. Although these effects cannot reliably predict an in vivo efficacy of such a strategy, the pathway identified may help design therapeutic treatments aimed to limit the metastatic potential of these endocrine tumour cells and improve the outcome of patients affected by this rare disease.

\section{Acknowledgements}

We wish to thank Dr Maria Paola Paronetto for the pGEX4T1-SrcSH2 plasmid, Dr Daniela Barilà for pCMV5-chSrc, Federica Capolunghi and Rita Carsetti for help with FACs analysis, Prof. Massimo De Felici for reagents and suggestions with the adhesion assays, Prof. Andrea Modesti for providing collagen IV and fibronectin. This work was supported by grants from AIRC (Associazione Italiana Ricerca sul Cancro) and Ministry of Education (PRIN 2004) to C S. The authors declare that there is no conflict of interest that would prejudice the impartiality of this scientific work.

\section{References}

Ambrogio C, Vogna C, Manazza AD, Riera L, Barberis L, Costa C, Tarone G, De Filippi G, Hirsch E, Erba EB et al. 2005 p130Cas mediates the transforming properties of the anaplastic lymphoma kinase. Blood 106 3907-3916.

Baroni MG, Cavallo MG, Mark M, Monetin L, Stoehrer B \& Pozzilli P 1999 Beta-cell gene expression and functional characterisation of the human insulinoma cell line CM. Journal of Endocrinology 161 59-68.

Bouton AH, Riggins RB \& Bruce-Staskal PJ 2001 Functions of the adapter protein Cas: signal convergence and the determination of cellular responses. Oncogene 20 6448-6458.

Brunton VG, Avizienyte E, Fincham VJ, Serrels B, Metcalf A, III, Sawyer TK \& Frame MC 2005 Identification of Src-specific phosphorylation site on focal adhesion kinase: dissection of the role of $\mathrm{Src} \mathrm{SH} 2$ and catalytic functions and their consequences for tumor cell behavior. Cancer Research 65 1335-1342.

Cabodi S, Tinnirello A, Di Stefano P, Bisaro B, Ambrosino E, Castellano I, Sapino A, Arisio R, Cavallo F, Forni G et al.
2006 p130Cas as a new regulator of mammary epithelial cell proliferation, survival, and HER2-Neu oncogene-dependent breast tumorigenesis. Cancer Research 66 4672-4680.

Calalb M, Polte TR \& Hanks SK 1995 Tyrosine phosphorylation of focal adhesion kinase at sites in the catalytic domain regulates kinase activity: a role for Src family kinases. Molecular and Cellular Biology 15 954-963.

Capurso G, Crnogorac-Jurcevic T, Milione M, Panzuto F, Campanini N, Dowen SE, Di Florio A, Sette C, Bordi C, Lemoine NR et al. 2005 Peanut-like 1 (septin 5) gene expression in normal and neoplastic human endocrine pancreas. Neuroendocrinology 81 311-321.

Capurso G, Lattimore S, Crnogorac-Jurcevic T, Panzuto F, Milione M, Bhakt V, Campanini N, Swift MS, Bordi C, Delle Fave G et al. 2006 Gene expression profiles of progressive pancreatic endocrine tumours and their liver metastases reveal potential novel markers and therapeutic targets. Endocrine-Related Cancer 13 541-558.

Castoria G, Migliaccio A, Bilancio A, Di Domenico M, de Falco A, Lombardi M, Fiorentino R, Varricchio L, Barone MV \& Auricchio F 2001 PI3-kinase in concert with Src promotes the S-phase entry of estradiol-stimulated MCF-7 cells. EMBO Journal 20 6050-6059.

Cavallaro U \& Christofori G 2004 Cell adhesion and signalling by cadherins and Ig-CAMs in cancer. Nature Reviews. Cancer 4 118-132.

Duxbury MS, Ito H, Ashley SW \& Wang EE 2004a c-Srcdependent cross-talk between CEACAM6 and alphavbeta3 integrin enhances pancreatic adenocarcinoma cell adhesion to extracellular matrix components. Biochemical and Biophysical Research Communications 317 133-141.

Duxbury MS, Ito H, Zinner MJ, Ashley SW \& Wang EE $2004 b$ Inhibition of SRC tyrosine kinase impairs inherent and acquired gemcitabine resistance in human pancreatic adenocarcinoma cells. Clinical Cancer Research $\mathbf{1 0}$ 2307-2318.

Ezzat S \& Asa SL 2005 The molecular pathogenetic role of cell adhesion in endocrine neoplasia. Journal of Clinical Pathology 58 1121-1125.

Giancotti FG \& Tarone G 2003 Positional control of cell fate through joint integrin/receptor protein kinase signaling 1994. Annual Review of Cell and Developmental Biology 19 173-206.

Golas JM, Lucas J, Etienne C, Golas J, Discafani C, Sridharan L, Boghaert E, Arndt K, Ye F, Boschelli DH et al. 2005 SKI-606, a Src/Abl inhibitor with in vivo activity in colon tumor xenograft models. Cancer Research 65 5358-5364.

Hanket JH, Gardner JP, Dow RL, Changelian PS, Brissette WH, Weringer EJ, Pollok BA \& Connelly PA 1996 Discovery of a novel, potent, and src family-selective tyrosine kinase inhibitor. Journal of Biological Chemistry 271 695-701.

Hanks SK, Calalb MB, Harper MC \& Patel SK 1992 Focal adhesion protein-tyrosine kinase phosphorylated in response to cell attachment to fibronectin. PNAS $\mathbf{8 9}$ 8487-8491. 
Hansel DE, Rahman A, House M, Ashfaq R, Berg K, Yeo CJ \& Maitra A 2004 Met proto-oncogene and insulin-like growth factor binding protein 3 overexpression correlates with metastatic ability in well-differentiated pancreatic endocrine neoplasms. Clinical Cancer Research 10 6152-6158.

Iguchi H, Hayashi I \& Kono A 1990 A somatostatin-secreting cell line established from a human pancreatic islet cell carcinoma (somatostatinoma): release experiment and immunohistochemical study. Cancer Research $\mathbf{5 0}$ 3691-3693.

Irby RB \& Yeatman TJ 2000 Role of Src expression and activation in human cancer. Oncogene 19 5636-5642.

Irby RB, Mao W, Coppola D, Kang J, Loubeau JM, Trudeau W, Karl R, Fujita DJ, Jove R \& Yeatman TJ 1999 Activating SRC mutation in a subset of advanced human colon cancers. Nature Genetics 21 187-190.

Maitra A, Hansel DE, Argani P, Ashfaq R, Rahman A, Naji A, Deng S, Geradts J, Hawthorne L, House MG et al. 2003 Global expression analysis of well-differentiated pancreatic endocrine neoplasms using oligonucleotide microarrays. Clinical Cancer Research 9 5988-5995.

Malliri A \& Collard JG 2003 Role of Rho-family protein in cell adhesion and cancer. Current Opinion in Cell Biology 15 583-589.

McLean GW, Avizienyte E \& Frame MC 2003 Focal adhesion kinase as a potential target in oncology. Expert Opinion on Pharmacotherapy 4 227-234.

O’Neill GM, Fashena SJ \& Golemis EA 2000 Integrin signalling: a new Cas $(\mathrm{t})$ of characters enters the stage. Trends in Cell Biology 10 111-119.

O’Toole D, Hentic O, Corcos O \& Ruszniewski P 2004 Chemotherapy for gastro-enteropancreatic endocrine tumours. Neuroendocrinology 80 779-784.

Panzuto F, Nasoni S, Falconi M, Corveto VD, Capurso G, Cassetta S, Di Fonzo M, Tornatore V, Milione M, Angeletti S et al. 2005 Prognostic factors and survival in endocrine tumor patients: comparison between gastrointestinal and pancreatic localization. Endocrine-Related Cancer 12 1083-1092.

Panzuto F, Di Fonzo M, Pannicelli E, Sciuto R, Maini CL, Capurso G, Milione M, Cattaruzza MS, Falconi M, David V et al. 2006 Long-term clinical outcame of somatostatin analogues of progressive, metastatic, welldifferentiated entero-pancreatic endocrine carcinoma. Annals of Oncology 17 461-466.

Playford MP \& Schaller MD 2004 The interplay between Src and integrins in normal and tumor biology. Oncogene $\mathbf{2 3}$ 7928-7946.

Plockinger U, Rindi G, Arnold R, Eriksson B, Krenning EP, de Herder WW, Goede A, Caplin M, Oberg K, Reubi JC et al. 2004 European Neuroendorine Tumor Society. Guidelines for diagnosis and treatment of neuroendocrine gastrointestinal tumors. A consensus statement on behalf of the European Neuroendorine Tumor Society (ENETS). Neuroendocrinology 80 394-424.
Ponniah S, Wang DZ, Lim KL \& Pallen CJ 1999 Targeted distruption og the tyrosine phosphatase PTPalpha leads to constitutive downregulation of the kinases Src and Fyn. Current Biology 9 535-538.

Rohrschneider LR 1980 Adhesion plaques of Rous sarcoma virus-transformed cells contain the $\operatorname{src}$ gene product. PNAS 77 3514-3518.

Schaller MD, Hildebrand JD, Shannon JD, Fox JW, Vines RR \& Parsons JT 1994 Autophosphorylation of the focal adhesion kinase, pp125FAK, directs SH2-dependent binding of pp60Src. Molecular and Cellular Biology 14 1680-1688.

Schlaplafer D, Hanks SK, Hunter T \& van der Geer P 1994 Integrin-mediated signal transduction linked to Ras pathway by GRB2 binding to focal adhesion kinase. Nature 372 786-791.

Sette C, Bevilacqua A, Geremia R \& Rossi P 1998 Involvement of phospholipase Cgamma1 in mouse egg activation induced by a truncated form of the C-kit tyrosine kinase present in spermatozoa. Journal of Cell Biology 142 1063-1074.

Sette C, Paronetto MP, Barchi M, Bevilacqua A, Geremia R \& Rossi P 2002 Tr-kit-induced resumption of the cell cycle in mouse eggs requires activation of a Src-like kinase. EMBO Journal 21 5386-5395.

Solcia E, Klöppel G, Sobin LH \& in collaboration with 9 Pathologists from 4 Countries 2000 Histological Typing of Endocrine Tumors. 2 World Health Organization 2000. Berlin Heidelberg New York: Springer Verlag pp 1-5.

Thomas SM \& Brugge JS 1997 Cellular functions regulated by Src family kinases. Annual Review of Cell and Developmental Biology 13 513-609.

Thomas JW, Ellis B, Boerner RJ, Knight WB, White GC, II \& Schaller MD 1998 SH2-, and SH3- mediated interactions between focale adhesion kinase and Src. Journal of Biological chemistry 273 577-583.

Tomassetti P, Campana D, Piscitelli L, Casadei R, Santini D, Nori F, Morselli-Labate AM, Pezzilli R \& Corinaldesi R 2005 Endocrine pancreatic tumors: factors correlated with survival. Annals of Oncology 16 1806-1810.

Webb DJ, Donais K, Whitmore LA, Thomas SM, Turner CE, Parsons J \& Horwitz AF 2004 FAK-Src signalling through paxillin, ERK, MLCK regulates adhesion disassembly. Nature Cell Biology 6 154-161.

Weber TK, Steele G \& Summerhayes IC 1992 Differential pp60 c-src activity in well and poorly differentiated human colon carcinomas and cell lines. Journal of Clinical Investigation 90 815-821.

Yeatman TJ 2004 A renaissance for SRC. Nature Reviews. Cancer 4 470-480.

Yezhelyev V, Koehl G, Guba M, Brabletz T, Jauch KW, Ryan A, Barge A, Green T, Fennell M \& Bruns CJ 2004 Inhibition of SRC tyrosine kinase as treatment for human pancreatic cancer growing orthotopically in nude mice. Clinical Cancer Research 10 8028-8036. 